\title{
Milk-induced Eczema Is Associated with the Expansion of T Cells Expressing Cutaneous Lymphocyte Antigen
}

Katherine J. Abernathy-Carver, ${ }^{\star \ddagger}$ Hugh A. Sampson, ${ }^{5}$ Louis J. Picker," and Donald Y. M. Leung *

*Department of Pediatrics, The National Jewish Center for Immunology and Respiratory Medicine, Denver, Colorado 80206;

${ }^{\ddagger}$ Department of Pediatrics, University of Colorado Health Sciences Center, Denver, Colorado 80262; ${ }^{\S}$ Johns Hopkins University School

of Medicine, Baltimore, Maryland 21205; and "Laboratory of Experimental Pathology, Department of Pathology, University of Texas

Southwestern Medical Center, Dallas, Texas 75235

\begin{abstract}
The extravasation of $T$ cells at sites of inflammation is critically dependent on the activity of homing receptors (HR) involved in endothelial cell recognition and binding. Two such HR (the cutaneous lymphocyte antigen [CLA] and Lselectin) have been shown to be selectively involved in $T$ cell migration to skin and peripheral lymph nodes, respectively. This study was designed to assess the relationship between the organ specificity of an allergic reaction to food and the expression of $H R$ on $T$ cells activated in vitro by the relevant food allergen. Peripheral blood mononuclear cells were isolated from seven milk allergic children with a history of eczema when exposed to milk. All patients had a positive prick skin test and double-blind placebo-controlled food challenge to milk. 10 children with either allergic eosinophilic gastroenteritis or milk-induced enterocolitis and 8 nonatopic adults served as controls. Five-parameter flow cytometry using monoclonal antibodies was used for detection of the specific HR on freshly isolated $T$ cells versus $T$ cell blasts induced by a 6-d incubation with casein, as compared with Candida albicans.

After in vitro stimulation with casein, but not $C$. albicans, patients with milk allergy and atopic dermatitis had a significantly greater percentage of $\mathrm{CLA}^{+} \mathrm{T}$ cells $(P$ $<0.01$ ) than controls with milk-induced enterocolitis, allergic eosinophilic gastroenteritis, or nonatopic healthy controls. In contrast, the percentage of $L$-selectin-expressing $T$ cells did not differ significantly between these groups. These data suggest that after casein stimulation allergic patients with milk-induced skin disease have an expanded population of $\mathrm{CLA}^{+} \mathrm{T}$ cells, as compared with nonatopics or allergic patients without skin involvement. We postulate that heterogeneity in the regulation of $H R$ expression on antigen-specific $\mathbf{T}$ cells may play a role in determining sites
\end{abstract}

Address correspondence to Donald Y. M. Leung, M.D., Ph.D., Department of Pediatrics, National Jewish Center for Immunology and Respiratory Medicine, 1400 Jackson St., Denver, CO 80206. Phone: 303-3981186; FAX: 303-270-2182.

Received for publication 25 August 1994 and in revised form 7 November 1994.

J. Clin. Invest.

(C) The American Society for Clinical Investigation, Inc. 0021-9738/95/02/0913/06 \$2.00

Volume 95, February 1995, 913-918 of involvement in tissue-directed allergic responses. (J. Clin. Invest. 1995. 95:913-918.) Key words: eczema • skin • T cells $\cdot$ milk $\cdot$ homing

\section{Introduction}

During the past decade, there have been several major breakthroughs in our understanding of the immunologic mechanisms which result in chronic allergic diseases such as atopic dermatitis $(\mathrm{AD})^{1}$ and asthma. Patients with allergic diseases have in common the propensity to produce IgE responses to specific allergens and develop local tissue inflammation characterized by the infiltration of activated $\mathrm{HLA}-\mathrm{DR}^{+}, \mathrm{CD} 4^{+}, \mathrm{CD} 45 \mathrm{RO}^{+}$ memory/effector $\mathrm{T}$ cells and eosinophils $(1,2)$. In situ hybridization studies of airway cells and skin biopsies, respectively, from patients with asthma and $\mathrm{AD}$, have revealed that $\mathrm{T}$ cells infiltrating into sites of allergic reactions express $\mathrm{T}$ helper type $2\left(\mathrm{~T}_{\mathrm{H}} 2\right)$-like cytokine profiles, i. e., increased mRNA expression for IL-4 and IL-5 but not IFN- $\gamma(3,4)$. Furthermore, allergen-specific $\mathrm{T}$ cells grown from peripheral blood and diseased tissues of patients with various allergic diseases have been found to express $T_{H} 2$-like cytokines $(5-7)$. These $T_{H} 2$ cells have been shown to promote IL-4-dependent IgE synthesis and IL-5-dependent eosinophil differentiation (5).

Despite these important insights into the generic allergic response, there is little information regarding the mechanisms which determine tissue specificity of particular $\mathrm{T}$ cell responses in different allergic diseases. Studies in animal models have demonstrated clear heterogeneity in the ability of previously activated $\mathrm{T}$ lymphocytes to migrate to mucosal versus nonmucosal sites (for review see reference 8). This tissue-selective homing is regulated in large part at the level of lymphocyte recognition of post-capillary venular endothelial cells (EC) via the interaction of differentially expressed lymphocyte homing receptors (HR) and their EC ligands $(9,10)$. In humans, lymphocyte/EC adhesion molecule pairs thought to participate in tissue-selective lymphocyte homing include the skin-selective HR called the cutaneous lymphocyte-associated antigen (CLA) and the peripheral lymph node HR, L-selectin (8-13).

Recently, we have found that $T$ cells migrating into skin blisters overlying cutaneous delayed-type hypersensitivity reac-

1. Abbreviations used in this paper: $\mathrm{AD}$, atopic dermatitis; $\mathrm{AEG}$, allergic eosinophilic gastroenteritis; CLA, cutaneous lymphocyte-associated antigen; EC, endothelial cell; $\mathrm{HR}$, homing receptor; $\mathrm{TH}_{2}, \mathrm{~T}$ helper type 2 . 
Table I. Clinical and Laboratory Features of Subjects

\begin{tabular}{|c|c|c|c|c|}
\hline Subject group & $n$ & Median age (range) & Mean IgE CAP to milk & Symptoms after milk challenge \\
\hline $\begin{array}{l}\text { Atopic dermatitis and milk- } \\
\text { induced eczema }\end{array}$ & 7 & $5(3-12 y r)$ & $33.01 \pm 13.77 \mathrm{kU}_{\mathrm{A}} /$ liter & $\begin{array}{l}\text { Exacerbation of eczema, hives, vomiting, } \\
\text { angioedema }\end{array}$ \\
\hline Milk-induced enterocolitis & 6 & $5(14 \mathrm{mo}-9 \mathrm{yr})$ & $7.96 \pm 7.27 \mathrm{kU}_{\mathrm{A}} /$ liter & $\begin{array}{l}\text { Hives, abdominal pain, vomiting, } \\
\text { lethargy, diarrhea }\end{array}$ \\
\hline Eosinophilic gastroenteritis & 4 & $3(3-14 y r)$ & $5.08 \pm 3.09 \mathrm{kU}_{\mathrm{A}} /$ liter & $\begin{array}{l}\text { Hives, sneezing, vomiting, anaphylaxis, } \\
\text { laryngeal edema, diarrhea, no reaction. }\end{array}$ \\
\hline Nonatopic adults & 8 & $26(25-50 \mathrm{yr})$ & $<0.35 \mathrm{kU}_{\mathrm{A}} /$ liter & Not applicable \\
\hline
\end{tabular}

tions are highly enriched for the CLA expressing memory/ effector $\mathrm{T}$ cell subset, whereas memory/effector $\mathrm{T}$ cells isolated from the airways of asthmatics are predominantly CLA negative (14). Thus, the propensity of a given individual to develop AD as opposed to asthma may depend on differences in the skinor lung-seeking behavior of their memory/effector T cells (15). In children with $\mathrm{AD}$, food allergens (e. g., milk) have been found to be a well-defined trigger for eczema. In this study, we were therefore interested in determining whether there was a relationship between the tissue specificity of a clinical reaction to an allergen and the expression of $\mathrm{HR}$ on $\mathrm{T}$ cells activated in vitro by the relevant allergen. To this end, we assessed the expression of CLA and L-selectin on peripheral blood T cells from patients with $\mathrm{AD}$ and milk-induced eczema and compared their HR expression, at baseline and after stimulation with the major milk protein, casein, to $T$ cells collected from patients with allergic eosinophilic gastroenteritis (AEG), milk-induced enterocolitis, or nonatopic healthy controls. Our findings indicate that the casein-reactive $\mathrm{T}$ cells from patients with milkinduced eczema display significantly higher levels of CLA than Candida albicans-reactive $T$ cells from the same patients and either casein- or $C$. albicans-reactive $\mathrm{T}$ cells from nonatopic controls or noneczematous atopic patients. Thus, in the eczematous patients, the high CLA expression of casein-reactive cells may facilitate the localization of these $T$ cells in skin, thereby playing a key role in determining the predominantly cutaneous manifestation of their atopic disease.

\section{Methods}

Study populations. This study included blood samples obtained from children with milk-induced eczema, AEG, and milk-induced enterocolitis. Healthy adults with no known allergies served as a nonatopic control population. Clinical and laboratory features are summarized in Table I. In patients with milk-induced eczema, the diagnosis of $\mathrm{AD}$ was made according to the criteria of Hanifin and Rajka (16), and the diagnosis of IgE-mediated milk allergy was established by the presence of positive prick skin test to milk, presence of elevated milk-specific IgE antibodies in the serum, and positive double-blind placebo-controlled food challenges to milk, as previously described (17). Patients with AEG were diagnosed based on their presentation of recurrent abdominal pain, nausea, vomiting, early satiety, intermittent diarrhea, and failure to thrive, with extensive infiltration of mucosal biopsies of the esophagus, stomach, and small intestine with eosinophils (18). Clinical symptoms resolved with the institution of an elemental diet and recurred with doublebind placebo-controlled food challenge to milk. Patients diagnosed with milk-induced enterocolitis fulfilled the criteria of Powell (19): $(a)$ disappearance of vomiting, diarrhea, and guaiac-positive stools containing increased leukocytes after the removal of antigen (usually milk or soy formulas) from the diet; $(b)$ absence of symptoms and good weight gain for at least one month on a low-antigen formula (extensively hydrolyzed casein formula); and $(c)$ recurrence of symptoms and peripheral blood leukocytosis with food allergen challenge $(0.6 \mathrm{~g}$ protein $/ \mathrm{kg}$ body weight). Because of the limited amount of blood that could be obtained in children, it was not possible to carry out all the analyses on each child. Informed consent approved by The Johns Hopkins University School of Medicine in Baltimore or the National Jewish Center for Immunology and Respiratory Medicine in Denver, as appropriate, was obtained from all patients/parents before entry into this study.

Determination of sensitivity to milk. Patients' sera were tested for specific IgE levels to milk allergen using the CAP-RAST system (Pharmacia Diagnostic AB, Uppsala, Sweden). This is an in vitro test system for the determination of circulating specific IgE antibodies. The system uses solid phase bound allergens (immunoCAP) that react with antibodies in the serum samples. Units are expressed as $\mathbf{k U}_{\mathbf{A}} /$ liter where $\mathrm{A}$ represents allergen-specific antibody. Values $<0.35 \mathrm{kU}_{\mathrm{A}} /$ liter represent absent or undetectable levels of allergen-specific antibody. There is no cross-reactivity with IgA, IgD, IgM, or IgG.

In addition, all patients with milk-induced eczema, AEG, and enterocolitis underwent double-blind, placebo-controlled food challenges to verify their clinical sensitivity to milk. These challenges were carried out at The Johns Hopkins Clinical Research Center as described previously (17).

Cell culture. Peripheral blood mononuclear cells (PBMC) were isolated from heparinized venous blood by density gradient sedimentation over Ficoll-Hypaque (Histopaque; Sigma Chemical Co., St. Louis, MO). Cells were then washed three times in Hanks' balanced salt solution (Gibco Laboratories, Grand Island, NY) and resuspended in medium, as appropriate, for either cell culture or immunofluorescence staining.

For cell culture studies, PBMC at $1 \times 10^{6} / \mathrm{ml}$ cells were cultured in AIM-V media (Gibco Laboratories) with 1\% L-glutamine and $10 \%$ autologous plasma. Cells were cultured in the presence of casein (200 $\mu \mathrm{g} / \mathrm{ml}$; Sigma Chemical Co.) or $C$. albicans antigen $(8,060 \mathrm{pnu} / \mathrm{ml}$; Miles Pharmaceutical Division, Elkhart, IN) or no antigen for $6 \mathrm{~d}$. To assess proliferation, the cells $\left(2 \times 10^{4}\right.$ cells/well $)$ were placed in a 96well microtiter plate in triplicate and pulsed with $\left[{ }^{3} \mathrm{H}\right]$ thymidine (ICN Biomedicals, Irvine, CA) at $1 \mu \mathrm{Ci} /$ well for $6 \mathrm{~h}$. Incorporation of $\left[{ }^{3} \mathrm{H}\right]-$ thymidine was determined and expressed as the stimulation index (cpm with antigen/cpm without antigen). For immunofluoresence staining, cells were washed and resuspended in staining buffer (see below).

Monoclonal antibodies. mAbs Leu4 (CD3; peridinin chlorophyll- $\alpha$ protein, i. e., PerCP), Leu3a (CD4; FITC, PE), Leu2a (CD8; PE), Leu 45RO (CD45RO; PE), Leu8 (L-selectin; PE), anti-HLA-DR (PE), G1CL (mouse IgG1 control; FITC, PE), and G2G1 (mouse IgG2 control; FITC, PE) were obtained from Becton Dickinson Immunocytometry Systems (San Jose, CA). mAbs HECA-452 (a rat IgM against CLA; FITC) and MECA-79 (used as a rat IgM control; FITC) were prepared as previously described $(13,20)$.

Cell staining flow cytometry. Five parameter analysis was performed on a FACScan ${ }^{\oplus}$ flow cytometer (Becton Dickinson Immunocytometry systems) using FITC, PE, and PerCP as the three fluorescent parameters. Immunofluorescence staining for this multiparameter analysis was per- 
Table II. Antigen-specific PBMC Proliferation Responses

\begin{tabular}{cccc}
\hline & \multicolumn{2}{c}{ Total $\left[{ }^{3} \mathrm{H}\right]$ thymidine incorporation response } \\
\cline { 2 - 4 } Study group & Media & Casein & C. albicans \\
\hline $\begin{array}{c}\text { Milk-induced } \\
\text { eczema }(n=7)\end{array}$ & $2438 \pm 568$ & $48420 \pm 16837$ & $21853 \pm 9097 *$ \\
Gastroenteropathy & & & \\
$(n=10)$ & $1800 \pm 607$ & $48793 \pm 7835$ & $50874 \pm 11435$ \\
Normals $(n=8)$ & $2576 \pm 580$ & $37153 \pm 8341$ & $64791 \pm 11159$ \\
\hline
\end{tabular}

* $P=0.02$ as compared with normal controls.

formed as described previously $(13,20)$. Methods of cytometer setup and data acquisition have also been described previously (20). List mode multiparameter data files (each file with forward scatter, side scatter, and three fluorescent parameter) were analyzed using LYSIS II Windows program. Day 0 analysis was performed using a light scatter gate including only viable, small lymphocytes and a gate based on expression of CD3. For the day 6 analysis, the light scatter gate was set on the $\mathrm{T}$ cell blast population. Negative control reagents were used to verify the staining specificity of experimental antibodies.

Statistical analysis. Data are expressed as the mean \pm SEM for each patient population. Statistical comparisons were made using an unpaired two-tailed $t$ test with the Stat View 4.0 program on a Macintosh IIcx computer. Analysis of variance (ANOVA) was used to test differences in the means of three groups. When ANOVA was significant, a Fisher's multiple comparison procedure was used to determine which groups were significant at the $5 \%$ level. Differences between groups were considered significant at $P$ values $<0.05$.

\section{Results}

To determine whether PBMC from patients with milk-induced eczema respond to casein by selectively expanding their $\mathrm{CLA}^{+}$ $T$ cell subpopulation, we studied blood samples from three subject populations: first, a group of children with $\mathrm{AD}$ and milkinduced eczema confirmed by double-blind, placebo-controlled milk challenge; second, a group of children with gastroenteropathy that included patients with either AEG or milk-induced enterocolitis; and third, a group of normal adult subjects. As shown in Table II, PBMC from all three study groups proliferated equally well in response to casein. Although all three groups proliferated well to $C$. albicans, used as a control antigen in this study, PBMC from the AD group had decreased proliferation when compared with normal controls.

The expression of CLA was examined on freshly isolated peripheral blood $T$ cells versus $T$ cell blasts after $6 \mathrm{~d}$ of in vitro incubation with casein. At baseline, children with $\mathrm{AD}$ and milkinduced eczema had higher percentages of $\mathrm{CLA}^{+} \mathrm{T}$ cells in their PBMC than the other two subject groups. These baseline levels were significantly higher for children with $\mathrm{AD}$ as compared with children with gastroenteropathy $(P=0.005)$. After $6 \mathrm{~d}$ of in vitro incubation, the percentage of $\mathrm{CLA}^{+} \mathrm{T}$ cells rose in all three subject groups. However, as shown in Fig. 1, the level of $\mathrm{CLA}^{+} \mathrm{T}$ cell expansion was significantly higher for patients with milk-induced eczema compared with either the gastroenteropathy group $(P=0.001)$ or the nonatopic normal subjects $(P=0.004)$.

To determine whether this enhanced stimulation of $\mathrm{CLA}^{+} \mathrm{T}$ cells in patients with milk-induced eczema was antigen specific, PBMC from all three subject groups were also studied after stimulation with $C$. albicans. As shown in Fig. 2, C. albicans stimulated the expansion of $\mathrm{CLA}^{+} \mathrm{T}$ cells in all three subject groups to varying levels. However, after $6 \mathrm{~d}$ of stimulation with C. albicans, there were no significant differences between the three subject groups $(P=0.2$, ANOVA). More importantly, the percentage of $\mathrm{CLA}^{+} \mathrm{T}$ cells in PBMC from patients with milk-induced eczema was significantly greater $(P \leq 0.01)$ than each of the three control groups after in vitro stimulation with casein as compared with PBMC stimulated with $C$. albicans. Fig. 3 illustrates representative histograms demonstrating the expression of CLA on day 6 cells after stimulation with either casein or $C$. albicans. PBMC from the normal donor showed similar percentages of $\mathrm{CLA}^{+} \mathrm{T}$ cells in $C$. albicans-and caseinstimulated $T$ cells. In contrast, PBMC from the patient with milk-induced eczema had fourfold greater $\mathrm{CLA}^{+} \mathrm{T}$ cells on day 6 after in vitro stimulation with casein as compared with $C$. albicans.

Finally, we examined the expression of L-selectin on T cells before and after in vitro stimulation with casein. Incubation with casein did not significantly alter L-selectin expression in patients with casein-induced eczema. Furthermore, at baseline and after $6 \mathrm{~d}$ of incubation with casein, there was no significant differences in L-selectin expression found between patients with milk-induced eczema as compared with the other two study groups (see Fig. 4).

\section{Discussion}

Patients with an identified allergenic trigger of $\mathrm{AD}$ provide a unique model for studying the expression of various HR on T lymphocytes and their potential importance in the pathogenesis of allergic skin disease. In this study, we demonstrate that atopic children with milk-induced eczema exhibit a selective outgrowth of $\mathrm{CLA}^{+} / \mathrm{CD}^{+}{ }^{+}$memory/effector $\mathrm{T}$ cells in response to casein, but not $C$. albicans antigen, stimulation in vitro. Although patients with AEG, milk-induced enterocolitis, and healthy nonatopic controls exhibited casein-induced lymphocyte proliferation, these groups did not show a selective expansion of CLA-expressing $\mathrm{T}$ cells in response to casein stimulation. The specificity of the association between CLA expression on casein-reactive $T$ cells and skin disease is further supported by the observation that PBMC from children with $\mathrm{AD}$ and milkinduced eczema did not show selective expansion of $\mathrm{T}$ cells expressing the peripheral lymph node HR L-selectin as compared with the other control groups examined in this study. Given the close association between T cell CLA expression and skin localizing capability (11-14), these observations suggest that differential regulation of HR expression on antigen (allergen) reactive memory/effector $T$ cells may play a critical role in determining the clinical manifestations of atopic disease, in this case, allergen-induced eczema. The demonstration that $\mathrm{E}$ selectin, the vascular counter-receptor for CLA (21), is highly expressed on cutaneous venules in chronic $\mathrm{AD}(22)$ and therefore represents a plausible mechanism for the selective cutaneous extravasation of $\mathrm{CLA}^{+} \mathrm{T}$ cells supports this hypothesis, as does our previous observation that in contrast to $\mathrm{CLA}^{\text {high }}$ cutaneous $\mathrm{T}$ cells pulmonary $\mathrm{T}$ cells in the setting of asthma lack or express only low levels of CLA (14).

CLA is selectively expressed by a subset of CD45RO ${ }^{+}$ memory/effector $\mathrm{T}$ cells in the blood and essentially all such cells in skin, encompassing a wide variety of cutaneous inflammatory conditions in skin (including eczematous derma- 


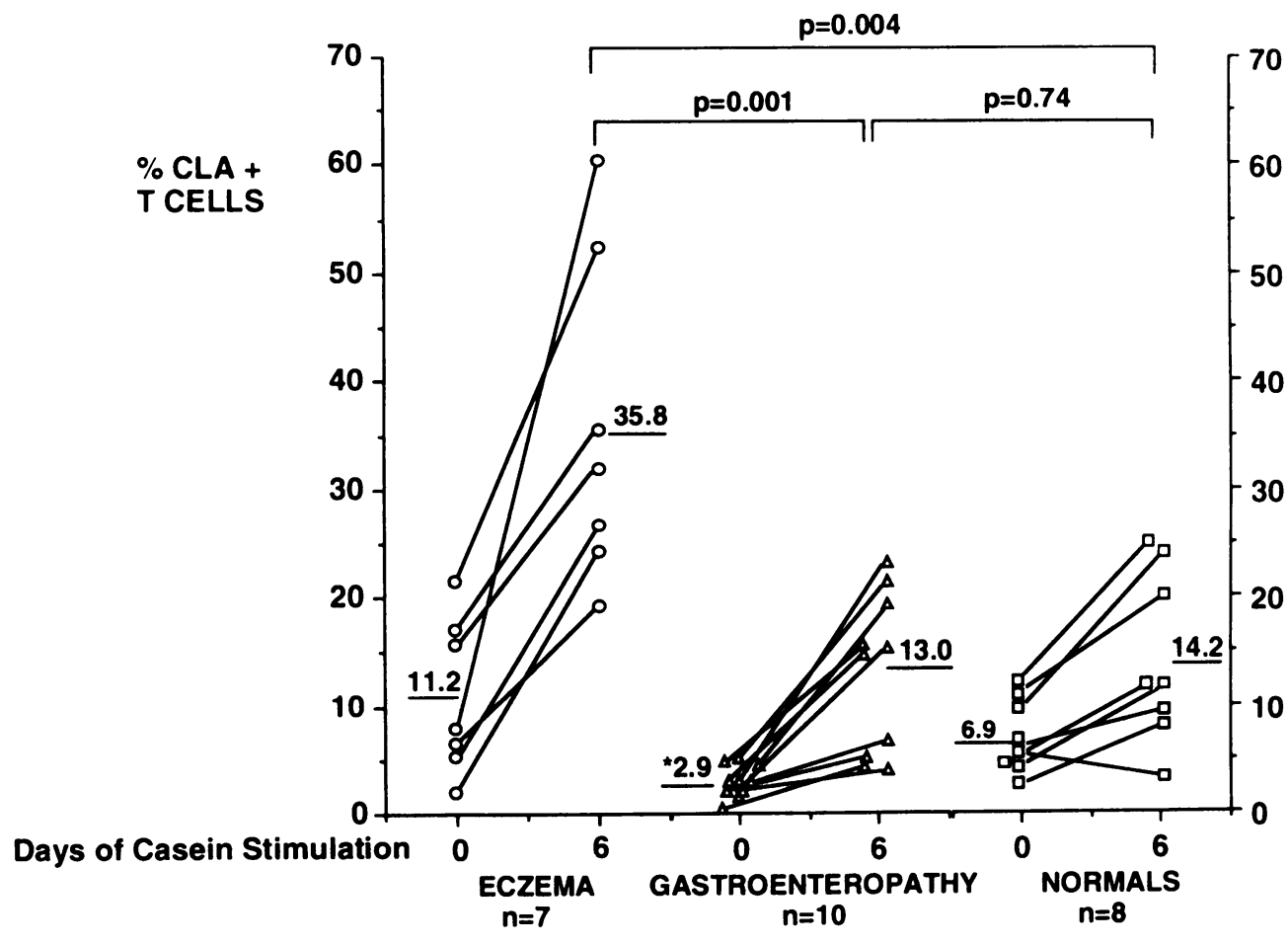

Figure 1. Casein induces $\mathrm{CLA}^{+} \mathrm{T}$ cell expression in patients with $\mathrm{AD}$ and milk-induced eczema. $\mathrm{CLA}^{+} \mathrm{T}$ cell expression was analyzed before (day 0 ) and after 6 $\mathrm{d}$ of in vitro stimulation with casein in seven patients with $A D$ and milk-induced eczema, 10 patients with gastroenteropathy, and 8 normal donors. At baseline, AD patients with milk-induced eczema had significantly greater $\left({ }^{*} P\right.$ $=0.005) \mathrm{CLA}^{+} \mathrm{T}$ cell expression than children with gastroenteropathy. After $6 \mathrm{~d}$ of casein stimulation, children with milk-induced eczema had significantly greater $\mathrm{CLA}^{+} \mathrm{T}$ cell expression than the other two control groups. titis ) $(11,12)$. It is not present on virgin $\mathrm{CD}^{2} 5 \mathrm{RO}^{-} \mathrm{T}$ cells, and, indeed, we have demonstrated that CLA is selectively upregulated during the antigen-induced virgin to memory/effector $\mathrm{T}$ cell conversion in secondary lymphoid tissue in a tissue-selective manner (12). In this regard, it is clear from studies in both animals and humans that the virgin to memory/effector conversion is a key regulatory point for $\mathrm{T}$ cell function in general, including regulation of HR expression and cytokine synthe-

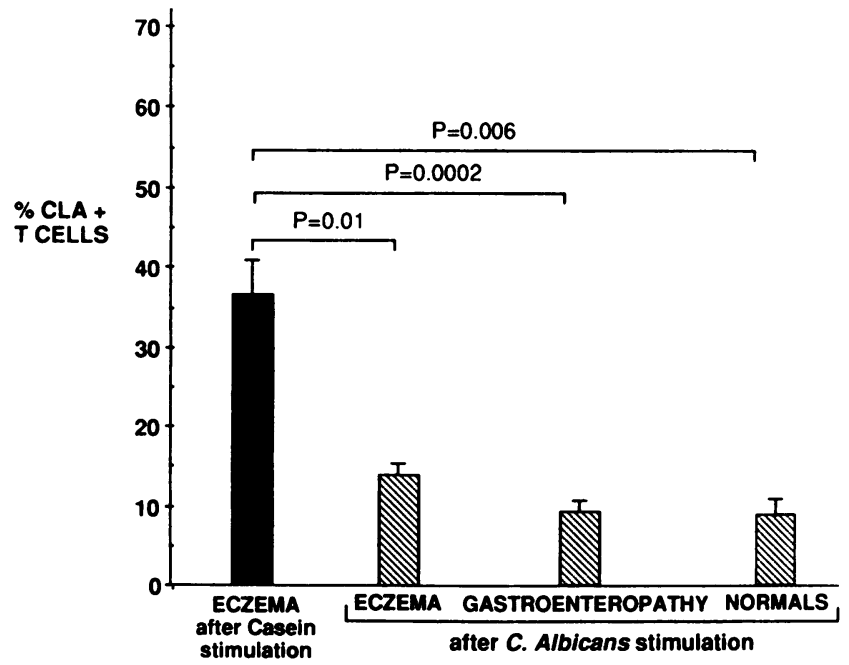

Figure 2. $\mathrm{CLA}^{+} \mathrm{T}$ cell expression after stimulation with casein versus C. albicans. CLA ${ }^{+} \mathrm{T}$ cell expression was determined in PBMC from either patients with milk-induced eczema, gastroenteropathy, or normals after $6 \mathrm{~d}$ of in vitro stimulation with either casein or $C$. albicans. Casein stimulation induced significantly greater $\mathrm{CLA}^{+} \mathrm{T}$ cell expression in the milk-induced eczema group as compared with $C$. albicans-induced PBMC from the three study groups.

sis potential (i. e., the $T_{H} 1$ vs. $T_{H} 2$ cytokine synthesis subsets) $(8,12,20)$. The regulatory elements directing homing and effector function in vivo are proving to be complex, involving

\section{Day 6 T cells (CD3 gated)}

\section{Candida Stimulated}

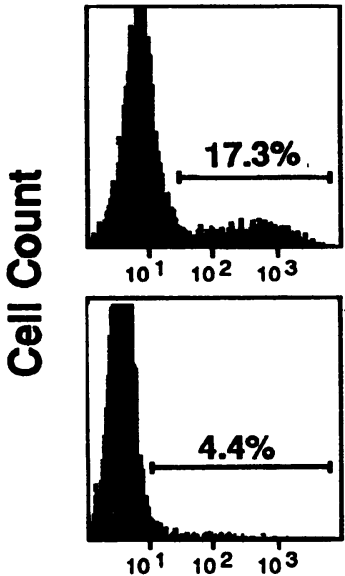

Casein Stimulated

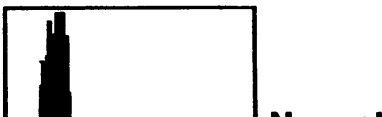

Normal

Figure 3. Casein, but not $C$. albicans, induces a higher percentage of $\mathrm{CLA}^{+} \mathrm{T}$ cells in a donor with milk-induced eczema than a normal donor. PBMC from a normal donor versus a patient with milk-induced eczema were stimulated for $6 \mathrm{~d}$ with either casein or $C$. albicans. Histograms were generated by gating on the $\mathrm{CD}^{+}$cells. PBMC from the normal donor had similar percentages of $\mathrm{CLA}^{+} \mathrm{T}$ cells after stimulation with casein versus $C$. albicans. In contrast, PBMC from the donor with milk-induced eczema had more than a fourfold higher percentage of $\mathrm{CLA}^{+} \mathrm{T}$ cells after stimulation with casein as compared with C. albicans. 


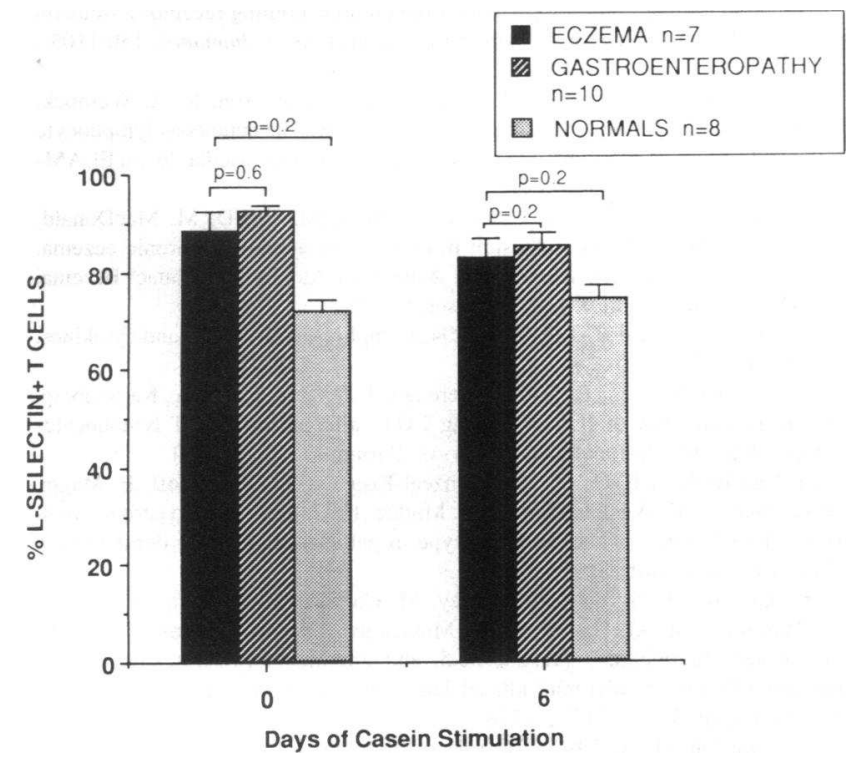

Figure 4. Expression of L-selectin on $\mathrm{T}$ cells before and after in vitro stimulation with casein. Incubation of PBMC from the three study groups with casein using the same culture conditions as in Fig. 1 did not induce significant alterations of L-selectin expression.

immunoregulatory cytokines, signals delivered via adhesion molecule ligation, and perhaps the nature of the antigenic stimulus itself (23). With regard to allergic disease, it is thought that IL-4 and IL-5 producing effector T cells (the so-called $\mathrm{T}_{\mathrm{H}} 2$ effector subset) play a critical etiologic role $(6,24-26)$, and microenvironmental conditions and/or genetic factors supporting the generation of such $\mathrm{T}_{\mathrm{H}} 2$ effectors during the virgin to memory/effector transition likely predispose to atopy in general. Here, we propose that the HR phenotype of the allergenspecific effector $T$ cells is independently regulated during the virgin to memory/effector conversion and plays a key role in determining (in conjunction with patterns of allergen deposition in the body) the particular tissue in which allergic reactions will manifest.

The functional manifestations of allergy-inducing $\mathrm{T}$ cell effectors may not be constant in a given individual but rather may be regulated continuously by the interplay between genetic, developmental, and environmental influences. AD and food allergy represent the earliest manifestation of allergic disease, occurring in infancy and early childhood (27), whereas allergic respiratory disease generally does not have its onset until after $5 \mathrm{yr}$ of age. Of interest, as AD patients develop asthma and allergic rhinitis, they frequently outgrow their eczema (28). Furthermore, it is well known that the offspring of patients with AD will predominantly have asthma or allergic rhinitis and not AD. The latter clinical observation suggests that, whereas the potential to develop allergen sensitization and manifest allergictype immune responses is inherited, the organ specificity of a particular allergic disease is acquired and determined by environmental factors. Since memory/effector $\mathrm{T}$ cells tend to express homing receptors that preferentially return them to extralymphoid tissues associated with the secondary lymphoid tissues in which they were first activated (8), the site of allergen exposure is likely to play a role in determining HR expression and hence the tissue pattern of atopic symptoms.

Although the gastrointestinal tract serves as a barrier to foreign proteins, early studies clearly demonstrated that immunologically intact food proteins enter the circulation and are distributed throughout the body. Prausnitz and Kustner (29) were the first to demonstrate the rapid absorption and transport of food antigens to passively sensitized skin sites. In a classic series of experiments, Walzer and his colleagues used sera from egg and fish allergic patients to passively sensitize volunteers (30-34). Adult volunteers were given intradermal injections of $0.05 \mathrm{~cm}^{3}$ of patient and control sera. Approximately $24 \mathrm{~h}$ later they were fed fish or eggs $(33,34)$. A wheal and flare reaction was noted at the sensitized skin site within several minutes to $1 \mathrm{~h}$ after ingestion of the relevant food in over $90 \%$ of subjects, but not at the control site. Using a similar sensitizing protocol and introducing food in specific locations along the gastrointestinal tract, it was shown that peanut antigen was rapidly absorbed from different locations in the gastrointestinal tract: oral cavity, $24.3 \mathrm{~min}$; duodenum, $18.6 \mathrm{~min}$; and rectum, $18.7 \mathrm{~min}$ (31). Taken together, these data indicate that after the oral ingestion of food, antigen can be deposited into the skin, thereby triggering dermal mast cells, and presumably processing of antigen by accessory cells in the skin-associated lymphoid tissue.

In summary, the current study provides new insights into potential mechanisms which determine the pathogenesis of allergic responses with different tissue specificities. Although the major focus of research in allergy has been on understanding the mechanism underlying IgE regulation, it is well known that although IgE responses are necessary they are not sufficient to account for chronic allergic disease. Indeed, a number of studies have demonstrated that even after patients outgrow their allergic disease, e. g., food allergy or inhalant allergy, either naturally or after immunotherapy that their allergen-specific IgE responses persist, as demonstrated by persistent positive immediate skin tests. The latter phenomenon was first coined by May and colleagues as "asymptomatic hypersensitivity" based on their observation that patients with positive food skin tests in $\mathrm{AD}$ frequently did not have positive challenges to the foods implicated by IgE responses (35). This suggests that other immune responses, perhaps $\mathrm{T}$ cell-mediated, are also important in regulating the development of "symptomatic hypersensitivity." The present findings provide an important new direction in which the mechanisms for this phenomenon can be studied.

\section{Acknowledgments}

The authors are grateful to Anne Trumble for technical assistance and Maureen Sandoval for her assistance in the preparation of this manuscript.

This study was supported in part by National Institutes of Health grants AR-41256, HL-36577, HL-37260, AI-31545, AI-24439, RR00051, and RR-00052.

\section{References}

1. Smith, D. L., and R. D. Deshazo. 1993. Bronchoalveolar lavage in asthma. Am. Rev. Respir. Dis. 148:523-532.

2. Leung, D. Y. M. 1992. Immunopathology of atopic dermatitis. Springer Semin. Immunopathol. 13:427-440.

3. Robinson, D. S., Q. Hamid, S. Ying, A. Tsicopoulos, J. Barkans, A. M. Bentley, C. Corrigan, S. R. Durham, and A. B. Kay. 1992. Predominant $\mathrm{T}_{\mathrm{H} 2}$-like bronchoalveolar T-lymphocyte population in atopic asthma. N. Engl. J. Med. 326:298-304.

4. Hamid, Q., M. Boguniewicz, and D. Y. M. Leung. 1994. Differential in situ cytokine gene expression in acute versus chronic atopic dermatitis. J. Clin. Invest. 94:870-876. 
5. Jabara, H. H., S. J. Ackerman, K. Arai, D. Vercelli, T. Yokota, J. Abrams, D. T. Umetsu, J. de Vries, D. Y. M. Leung, and R. S. Geha. 1988. Induction of IgE synthesis and of eosinophil differentiation in man by the supernatants of an IL-4 and IL-5 secreting helper T cell clone. J. Clin. Immunol. 8:437-448.

6. Wierenga, E. A., M. Snoek, C. deGroot, I. Chrètien, J. D. Bos, H. M. Jansen, and M. L. Kapsenberg. 1990. Evidence for compartmentalization of functional subsets of $\mathrm{CD}^{+}$T-lymphocytes in atopic patients. J. Immunol. 144:46514656.

7. Parronchi, P., D. Macchia, M.-P. Piccinni, P. Biswas, C. Simonelli, E. Maggi, M. Ricci, A. A. Ansari, and S. Romagnani. 1991. Allergen- and bacterial antigen-specific T-cell clones established from atopic donors show a different profile of cytokine production. Proc. Natl. Acad. Sci. USA. 88:4538-4542.

8. Picker, L. J., and E. C. Butcher. 1992. Physiological and molecular mechanisms of lymphocyte homing. Annu. Rev. Immunol. 10:561-591.

9. Picker, L. J. 1992. Mechanisms of lymphocyte homing. Curr. Opin. Immunol. 4:277-286.

10. Shimizu, Y., W. Newman, Y. Tanaka, and S. Shaw. 1992. Lymphocyte interactions with endothelial cells. Immunol. Today. 13:106-112.

11. Picker, L. J., S. A. Michie, L. S. Rott, and E. C. Butcher. 1990. A unique phenotype of skin-associated lymphocytes in humans: preferential expression of the HECA-452 epitope by benign and malignant T-cells at cutaneous sites. Am. J. Pathol. 136:1053-1058.

12. Picker, L. J., J. R. Treer, B. Ferguson-Darnell, P. A. Collins, P. R. Bergstresser, and L. W. M. M. Terstappen. 1993. Control of lymphocyte recirculation in man. II. Differential regulation of the cutaneous lymphocyte-associated antigen, a tissue-selective homing receptor for skin-homing T cells. J. Immunol. 150:11221136.

13. Picker, L. J., T. K. Kishimoto, C. W. Smith, R. A. Warnock, and E. C. Butcher. 1991. ELAM-1 is an adhesion molecule for skin-homing T cells. Nature (Lond.). 349:796-811.

14. Picker, L. J., R. J. Martin, A. E. Trumble, L. Newman, P. A. Collins, P. R. Bergstresser, and D. Y. M. Leung. 1994. Control of lymphocyte recirculation in man: differential expression of homing-associated adhesion molecules by memory/effector T cells in pulmonary vs. cutaneous effector sites. Eur. J. Immunol. 24:1269-1277.

15. Berman, J. S., D. J. Beer, A. C. Theodore, H. Kornfeld, J. Bernardo, and D. M. Center. 1990. Lymphocyte recruitment to the lung. Am. Rev. Respir. Dis. 142:238-257.

16. Hanifin, J. M., and G. Rajka. 1980. Diagnostic features of atopic dermatitis. Acta Dermato-Venereol. Suppl. 92:44-47.

17. Sampson, H. A., and P. L. Jolie. 1984. Increased plasma histamine concentrations after food challenges in children with atopic dermatitis. N. Engl. J. Med. 311:372-376.

18. Katz, A. J., F. J. Twarog, R. S. Zeiger, and Z. M. Falchuk. 1984. Milksensitive and eosinophilic gastroenteropathy: similar clinical features with contrasting mechanisms and clinical course. J. Allergy Clin. Immunol. 74:72-78.

19. Powell, G. K. 1986. Food protein-induced enterocolitis of infancy: differential diagnosis and management. Compr. Ther. 12:28-37.

20. Picker, L. J., J. R. Treer, B. Ferguson-Darnell, P. A. Collins, D. Buck, and L. W. M. M. Terstappen. 1993. Control of lymphocyte recirculation in man.
I. Differential regulation of the peripheral lymph node homing receptor L-selectin on $T$ cells during the virgin to memory cell transition. J. Immunol. 150:11051121.

21. Berg, E. L., T. Yoshino, L. S. Rott, M. K. Robinson, R. A. Warnock, T. K. Kishimoto, L. J. Picker, and E. C. Butcher. 1991. The cutaneous lymphocyte antigen, CLA, is a skin lymphocyte homing receptor for the vascular lectin ELAM1. J. Exp. Med. 174:1461-1466.

22. Groves, R. W., M. H. Allen, D. O. Haskard, and D. M. MacDonald. 1991. Endothelial leukocyte adhesion molecule-1 in acute and chronic eczema. In Immunological and Pharmacological Aspects of Atopic and Contact Eczema. J. M. Czernielewski, editor. Karger/Basel. 85-88.

23. Paul, W. E., and R. A. Seder. 1994. Lymphocyte responses and cytokines. Cell. 76:241-251.

24. Van der Heijden, F., E. A. Wierenga, J. D. Bos, and J. L. Kapsenberg. 1991. High frequency of IL-4 producing CD4+ allergen-specific T lymphocytes in atopic dermatitis lesional skin. J. Invest. Dermatol. 97:389-394.

25. Van Reijsen, F. C., C. A. Bruijnzeel-Koomen, F. S. Kalthoff, E. Maggi, S. Romagnani, J. K. Westland, and G. C. Mudde. 1992. Skin-derived aeroallergenspecific T-cell clones of the $\mathrm{T}_{\mathrm{h} 2}$ phenotype in patients with atopic dermatitis. $J$. Allergy Clin. Immunol. 90:184-193.

26. Kay, A. M., S. Ying, V. Varney, M. Gaga, S. R. Durham, R. Moqbel, A. J. Wardlaw, and Q. Hamid. 1991. Messenger RNA expression of cytokine gene cluster, interleukin 3 (IL-3), IL-5, and granulocyte/macrophage colonystimulating factor, in allergen-induced late-phase cutaneous reactions in atopic subjects. J. Exp. Med. 173:775-778.

27. Sampson, H. A. 1993. The role of allergens in atopic dermatitis. Clin. Rev. Allergy. 11:471-490.

28. Rajka, G. 1989. Pathomechanism: genetic and immunological factors. In Essential Aspects of Atopic Dermatitis. G. Rajka, editor. Springer-Verlag/Berlin. 74-154.

29. Prausnitz, C., and H. Kustner. 1921. Studies on supersensitivity. Zentralbl. Bakteriol. Parasitenkd. Infektionskr. Hyg. Abt. 86:160-169.

30. Walzer, M. 1927. Studies in absorption of undigested proteins in human beings. I. A simple direct method of studying the absorption of undigested protein. J. Immunol. 14:143-174.

31. Gray, I., and M. Walzer. 1940. Studies in absorption of undigested proteins in human beings. VIII. Absorption from the rectum and a comparative study of absorption following oral, duodenal, and rectal administrations. J. Allergy. 11:245-250.

32. Walzer, M. 1941. Allergy of the abdominal organs. J. Lab. Clin. Med. 26:1867-1877.

33. Brunner, M., and M. Walzer. 1928. Absorption of undigested proteins in human beings: the absorption of unaltered fish protein in adults. Arch. Intern. Med. 42:173-179.

34. Wilson, S. J., and M. Walzer. 1935. Absorption of undigested proteins in human beings. IV. Absorption of unaltered egg protein in infants. Am. J. Dis. Child. 50:49-54.

35. May, C. E. 1976. Objective clinical and laboratory studies of immediate hypersensitivity reactions to foods in asthmatic children. J. Allergy Clin. Immunol. 58:500-515. 